\title{
Modernizing the University Library Structure
}

\begin{abstract}
A Mong the several kinds of change that appear to be in order in personnel management in university libraries, some have been described, others have not. There has perhaps been a superabundance of attention devoted, for example, to the inadequate treatment of librarians within the university community as a whole, but little discussion has thus far appeared in print concerning their treatment within the library itself. This paper will attempt to define certain progressive changes that it is possible and probably desirable for the library to implement internally regardless of the university's willingness to consider improving the librarian's lot in the larger community.
\end{abstract}

A fundamental reform appears called for in the methodology of library governance itself. University libraries generally have long been administered through the traditional organizational structure. This classic structure comprises a pyramid of several horizontal levels, with the personnel at each level reporting to supervisors at the next level above, and each level of supervisors handing down instructions to the next level below. Information is passed up, and decisions are passed down. As long as communication is good, this kind of structure can result in an efficient operation. Communication in most university libraries has probably been fair, and the structure has probably served reasonably well.

Indeed the only disadvantage to this

Dr. Kaser is Director of Libraries, Cornell University. structure is that everyone has responsibility and voice only in the activities that fall directly below him in the pyramid; no one is expected to-nor has structured opportunity to-participate in the determination of library goals and standards outside of his own subordinate pyramid. Perhaps this limited participation is adequate and appropriate for the supporting staff, where skills and talents have been developed for use within a specific area of work activity. However, one of the distinguishing features of the professional staff member is that he has been broadly trained in the multifarious aspects of librarianship, regardless of the specific task to which he is currently assigned. For the professional, therefore, this failure to allow for widespread participation in the organization's total goal determination runs counter to the increasingly prevalent concept of librarianship as a high-order profession, wherein all practitioners are peers with equal obligation to speak out on library issues wherever in the total structure they happen to fall.

It is important to note that this essentially inimical relationship between the newer peer concept of a librarian's responsibility and his role in the traditional pyramidal structure is not limited to university libraries. This same conflict is increasingly in evidence throughout the library community-in other kinds of libraries, in library education, in the state and regional, and certainly in the national library associations. In this newer view librarians may no longer validly be thought of as "working for" a university library; rather 
they are the university library, and they share equally in the responsibility for its successes and failures wherever in the library system they happen to occur.

This problem is perhaps more acute in librarianship than it has been in other professions, since practitioners in other professions perform their daily work primarily alone. Doctors seldom work all day every day with large numbers of other doctors; most lawyers also work alone; ministers work alone. Thus decision making in other professions is primarily individual, as opposed to group, decision making. University librarians appear to be one of the few professional groups to perform their workaday activities in large teams, and, for whatever reason, they have never in the past pressed for an administrative structure uniquely appropriate to their peer status in these large organizations.

A major problem now before the academic library community, therefore, is to find a workable way to gain the involvement of the entire professional staff in appropriate library decision making in all areas and at all echelons. The absence of such a structure is doubtless a prime factor in the current trend in some large libraries toward unionization of the professional staff. It will not be enough to tell librarians that their views are welcome. A regular forum must be provided through which their views are sought. They must, moreover, feel secure in their obligation to express their views, a need which accounts in part for the present pressure for the establishment of a tenure-like mechanism in libraries to protect them from fear of retribution by a capricious administration.

This need for security might also call for rotating or elected department headships in large libraries, and certainly for greater attempt than there has been in the past to reward a librarian both financially and psychically for being a good librarian rather than for the ad- ditional administrative duties he assumes. Greater prestige must be attached to promotion in professional rank than in administrative rank, where the emoluments and status have resided in the past. Increased emphasis upon promotion in professional rank and salary regardless of administrative duties would benefit in other ways as well, since it would allow for the greater mobility of librarians into and out of administrative assignments. The basic salary structure could be tied entirely to rank and merit, with a fixed increment added while a librarian fills an administrative assignment, such as a department headship, in addition to his professional duties.

Psychic security in such a structure would seem also to be enhanced to a degree by the participation of nonadministrative personnel in the determination of promotion in rank. Criteria to be applied in appointment and promotion in rank need to be carefully spelled out, but presumably in one way or another they should take into account one's service to his user community, to the profession at large, and to society generally. These factors parallel roughly the "teaching, research, and public service" criteria widely used for professorial promotion in teaching faculties. Possibly an analogous practice might also be found in the teaching faculties for procedures as well as for criteria for promotion. A thought-provoking article on criteria for the promotion of librarians came out of the ACRL University Libraries Section's Committee on Academic Status a couple of years ago (CRL, September $1968,341-46)$. At the very least, modifications in practice regarding these matters seem to be called for.

Considering several of the unique aspects of the nature of research library work, namely-(1) that the work of librarians is professional work; but (2) that it must be accomplished in large organizations; where (3) a majority of staff members are not professional-it 
would appear that a traditional pyramidal structure will have to be maintained in university libraries, but that it might well function in parallel with a new peer group structure, rather than standing alone or by being superseded by a new structure. If this is to be done, it assumes that the two structures can be so ordered as not to be in conflict one with the other; that the activities necessary to the successful fulfillment of the research library's mission can be sorted meaningfully into two discrete groups each of which would be appropriate to only one of the two parallel structures.

Doubtless a sorting out of responsibilities would result in such matters being assigned to the peer structure as: the determination of standards of service, both institutional and personal, and the monitoring of those standards; the drafting of broad policies concerning the service thrust of librarianship at the university; the design of appropriate governance methodology. To the pyramidal structure, on the other hand, would be delegated the responsibility for effecting service, for the creation of procedures necessary for the implementation of policy, for the housekeeping functions attendant upon the successful operation of any large organization, and for the general supervision of supporting staff. The actual establishment of such a bipartite pattern of goal attainment in a university library, of course, would require a fuller and clearer delineation of responsibilities than is presented in this simple outline.

Insofar as an appropriate operating procedure for the peer structure is concerned, it would perhaps be difficult to find one better than a simple general assembly of librarians, working as necessary through committees. The relationship of the director of libraries to this general assembly would be quite similar to that of a dean to his faculty. Once policy and standard determination was concluded in the peer structure, how- ever, the decisions would be referred to the pyramidal structure for implementation, and the director of libraries would relinquish his "deanship" and would once again become a director. Likewise policy making at the department or division level would be accomplished by pertinent librarians as peers, with the department head acting as chairman; upon determination of policy, however, the department head would revert to his role as implementer rather than convener.

It is to be expected that there will be substantial counterforces militating against the successful establishment of such a bipartite governing structure. At least three come readily to mind; doubtless there are others.

1. There is in any university library a large, intelligent, educated and able supporting staff that may well feel that its decision-making participation ought also to be expanded; this may well be a justifiable claim, but if it is, it should be possible to see it accommodated through the pyramidal structure.

2. There are, unfortunately, some librarians in any organization who do not have the kind of strong dedication and professional commitment necessary to make the peer structure work; presumably a vigorous continuing education program and a brutal "up-or-out" personnel policy would tend over time to surmount this difficulty.

3. The traditional concept of success in libraries is based upon hierarchical promotion in administrative rank rather than upon progress up an academic ladder; care would have to be taken to assure widespread understanding of the academic-type ladder.

Another major barrier in the way of librarians' acceptance in the university community as high-order academic officers is the unfortunate emphasis still placed by some libraries upon their putting in a certain fixed number of hours per day or week at their desks. 
Librarianship of the kind needed today -which involves continuing research activities, professional updating, service in the larger community, and participation in decision-making as described above-simply cannot be satisfactorily accomplished by a clock-watching society. Librarians must recognize that their responsibilities extend through fully 168 hours per week whenever or to whatever degree in that period the need for their services demands.

In view of these concerns it seems incumbent upon library management to free up the schedules of its professional staff members as far as possible. In those libraries where such scheduling is a matter of management prerogative, it appears likely that it would be desirable to eliminate any reference to a specific number of hours in the work week of academic staff members and rely instead upon each individual librarian's concept of professional responsibility to determine his own work schedule. The purpose of this arrangement would be to allow to the academic staff member as much flexibility in determining his working hours as may be consonant with full performance of his duties.

It should be recognized from the outset that there are differences in competence, judgment, understanding, and self-discipline within any staff, but that nonetheless the responsibility for proper performance of duties in any professional position rests primarily with the individual concerned. It is, of course, a responsibility of supervisory personnel to be aware of the performance of those whose work they coordinate and to review it periodically and be prepared to lend such guidance as appears necessary. Continuing need for such guidance would, of course, place in doubt an individual's understanding of his role not only in the local library but also in the profession generally.

It should be assumed that each librarian, unless otherwise contractually agreed, is obligated to apply his full energies and attention to his duties broadly defined. Currently society seems to expect people to spend some thirtyfive to forty hours per week formally on duty. Understandably, however, a professional's concern for his dutieswhether he be a physician, a clergyman, or a librarian-does not start or stop at his office door nor at a specific hour of the day. It is rather a matter of professional conscience and the needs of the assignment he is responsible for fulfilling.

Librarians' assignments vary widely in their requirements. It should be recognized that hours scheduled on duty at public service points are necessary and obligatory. Also persons whose duties include direct and fairly continuous supervision of the work of others must clearly be on duty during most of the hours when their subordinates are scheduled. Effective performance moreover of the duties of nearly everyone requires quite regular availability for communication with other members of the staff, the community, and the public at large. One should therefore expect librarians ordinarily to be found, or findable, during a substantial part of what may be called normal office hours, except as specific schedules require otherwise. Indeed, it is likely that many people would choose to observe a schedule under the new policy that would be very similar to the one previously stipulated by the old policy.

The thrust of such an elimination of an official work week in libraries would be to transfer from library management to the individual and to the aforementioned peer structure the responsibility for determining the effective work load and standards of the organization. Management can rest assured that when the peer group participates in decisions on promotion in such a system, the occasional librarian who does not carry his full weight of responsibility will be uniformly passed over for promo- 
tion. Peer pressure is a much more effective instrument in this regard than is constant and expensive monitoring by the administration.

Such internal alterations as are proposed in this paper, when accompanied by full professional application and growth by the individual, can do much to gain wider-spread acceptance of librarians as colleagues by the teaching faculties. Appeals for faculty vote, tenure, sabbatical leaves, and other external perquisites of faculty status may well have been more often defeated by librarians' ill opinions and treatment of one another than by any inherent opposition to the notion in the minds of faculty. When faculty members hear appeals for access to their "club," they understandably look to the library to see who it is that is seeking status equal to their own. Instead of seeing a high order peer society, however, with a compelling sense of the urgency of their social mission, they too often see what appears to be a battery of high-priced clerks less interested in the total purpose of academic librarianship than in a routinized performance of menial tasks of concern only to themselves. Understandably they shun consorting with groups of such small-minded appearance. Our own houses, both collectively and individually, might well be put in order before we attempt to influence the ordering of others. 